\title{
PENINGKATAN SOFT SKILL PROPOSAL PENELITIAN BAGI MAHASISWA NUSA TENGGARA TIMUR
}

\author{
Tomy Michael \\ Fakultas Hukum, Universitas 17 Agustus 1945 Surabaya, Indonesia \\ tomy@untag-sby.ac.id
}

\begin{abstract}
ABSTRAK
Abstrak: Di dalam perkembangan dunia pendidikan yang terus berubah maka dibutuhkan pemahaman akan gagasan penelitian yang mutakhir. Gagasan peneltiian dalam lingkup pendidikan tinggi tercermin dalam proposal penelitian dimana mengacu Undang-Undang Republik Indonesia Nomor 12 Tahun 2012 tentang Pendidikan Tinggi (UU No. 12-2012) dijelaskan bahwa didalam mengembangkan bakat, minat serta kemampuan dirinya maka hal tersebut dapat dilakukan melalui kegiatan kokurikuler dan ekstrakurikuler. Kedua kegiatan itu dapat dilaksanakan melalui organisasi kemahasiswaan. Dalam pengabdian masyarakat ini para mahasiswa mendapatkan pemahaman secara komprehensif akan proposal peneltiian yang memenuhi kualifikasi Ristekdikti. Adanya perancangan proposal penelitian dan pemaparan secara individual menjadikan mahasiswa siap secara maksimal untuk mengetahui apakah penelitian yang digagasnya dapat dilaksanakan secara rasional atau tidak.
\end{abstract}

Kata Kunci: Proposal Penelitian, Soft Skill Mahasiswa

\begin{abstract}
In the development of an ever changing education world, it is necessary to understand the latest research ideas. The idea of research in the scope of higher education is reflected in research proposals which refer to the Law of the Republic of Indonesia Number 12 of 2012 on Higher Education (Law No. 12-2012) explained that in developing his talents, interests and abilities, this can be done through co-curricular activities. and extracurricular. Both activities can be carried out through student organizations. In this community service students gain a comprehensive understanding of research proposals that meet the Ristekdikti qualifications. The existence of individual research proposal design and presentation makes students optimally prepared to find out whether the research they initiated can be done rationally or not.
\end{abstract}

Keywords: Research Proposal, Student Soft skills

\section{A. LATAR BELAKANG}

Di dalam perkembangan dunia pendidikan yang terus berubah maka dibutuhkan pemahaman akan gagasan penelitian yang mutakhir. Gagasan penelitian dalam lingkup pendidikan tinggi tercermin dalam proposal penelitian dimana mengacu Undang-Undang Republik Indonesia Nomor 12 Tahun 2012 tentang Pendidikan Tinggi (UU No. 12-2012) dijelaskan bahwa didalam mengembangkan bakat, minat serta kemampuan dirinya maka hal tersebut dapat dilakukan melalui kegiatan kokurikuler dan ekstrakurikuler.

Kedua kegiatan itu dapat dilaksanakan melalui organisasi kemahasiswaan. Barbara mengatakan "Any organization is made of people and its success depends mainly on the capabilities of the human resources 
and on the kind of collaboration they are able to establish" (Cimatti, 2016). Mengacu Pasal 14 tersebut maka tiap mahasiswa wajib memiliki kemampuan mengembangkan bakat, minat dan kemampuan dirinya untuk tercapai disamping. Di Universitas 17 Agustus 1945 Surabaya (Untag Surabaya) yang mahasiswanya terdiri dari seluruh provinsi maka keberadaan suatu organisasi khususnya organisasi kepulauan yang tujuannya untuk tetap mengasimilasikan budaya lokal maka ada beberapa hal yang dilakukan antara lain seperti peningkatan soft skill disamping hard skill, memperluas jaringan serta manajemen konflik (Majid, Liming, Tong, \& Raihana, 2012).

Untag Surabaya yang memiliki jumlah kurang lebih 13.000 mahasiswa menjadikan pusat penyatuan beragam suku, agama, ras dan antar golongan yang menguatkan identitas sebagai Kampus Merah Putih. Atas dasar itulah, diadakan Bimbingan Teknis Berorganisasi Ikatan Keluarga Mahasiswa Nusa Tenggara Timur (IKM NTT).

\section{B. METODE PELAKSANAAN}

Menggunakan pola tatap muka dimana peneliti memberikan penjelasan awal, tanya jawab dan praktik membuat rancangan proposal yang terdiri dari judul, latar belakang, dan nilai lebih dibandingkan proposal lain sejenis. pengabdian masyarakat ini dilakukan kepada peserta yang terdiri dari mahasiswa Untag Surabaya yang berasal dari Nusa Tenggara Timur yang tergabung dalam IKM NTT dimana memiliki tujuan:

1. Merencanakan dan melaksanakan kegiatan kemahasiswaan yang tergabung dalam organisasi kemahasiswaan tingkat universitas dengan mengembangkan nalar dan keilmuan sesuai program studi masing-masing anggota

2. Menyelenggarakan proses kaderisasi organisasi tingkat program studi di Untag Surabaya

3. Berpartisipasi aktif dalam kegiatan perguruan tinggi seperti penelitian mandiri dan pengabdian kepada masyarakat

4. Membuat dan melaporkan pertanggungjawaban seluruh kegiatan kemahasiswaan dibawah organisasi kepada Ketua IKM NTT yaitu Kristoforus Laga Kleden.

Pengabdian ini berlangsung pada:

Tanggal : 23 Maret 2018

Jam : $: 09.00-16.30 \mathrm{WIB}$

Tempat : Ruang G301, Untag Surabaya

Jl. Semolowaru 45, Surabaya 60118

Peserta terdiri dari 15 mahasiswa 


\section{HASIL DAN PEMBAHASAN}

\section{Organisasi Dalam Lingkup Mahasiswa}

Mahasiswa sebagai bagian utama kehidupan berbangsa dan bernegara maka dibutuhkan suatu perubahan dalam menghasilkan keilmuan yang sesuai kebutuhan masyarakat. Di dalam pengabdian yang berfokus pada pembuatan proposal penelitian ini mengajak mahasiswa menghasilkan proposal penelitian yang sesuai standar Ristekdikti.

Proposal haruslah memiliki kebaruan dan keunggulan dibandingkan proposal lain sejenis. Proposal penelitian yang dibuat tidak sekadar sesuai minat mahasiswa namun bisa juga berkolaborasi dengan mahasiswa lainya yang memiliki jurusan berbeda.

Dari banyaknya argumen yang dikemukakan maka terdapat fakto lain yang mempengaruhi minat seorang mahasiswa untuk menghasilkan proposal penelitian yaitu menambah relasi karena dengan proposal yang dihasilkan maka akan dilakukan penelitian awal terlebih dahulu dengan melakukan konsultasi melalui dosen pembimbing dan subjek atau objek penelitian yang dikehendaki. Hal kedua yaitu adanya insentif bagi mahasiswa yang mampu mengunggah proposal sesuai standar Ristekdikti yaitu adanya halaman pengesahan, identitas dan uraian umum, daftar isi, ringkasan, pendahuluan, tinjauan pustaka, metode penelitian, biaya dan jadwal penelitian (anggaran biaya, jadwal penelitian) dan daftar pustaka (Direktorat Riset dan Pengabdian Masyarakat, Direktorat Jenderal Penguatan Riset dan Pengembangan Kementerian Riset, Teknologi, 2018). Untuk menghasilkan proposal penelitian ini maka dapat dilakukan dengan cara organisasi, berorganisasi dalam artikel ini berfokus pada IKM NTT dan terdapat suatu keuntungan bagi mahasiswa yaitu tema yang diangkat mengarah pada keindonesiaan dalam hal ini budaya, hukum adat, cerita rakyat dalam lingkup NTT. Berorganisasi akan menjadikan mahasiswa memiliki kemampuan komunikasi, emosi dan kedewasaan berpikir. Mereka juga akan banyak berinteraksi dengan orang lain yang memiliki latar belakang berbeda (Mustika Cahyaning Peritiwi, Awang Sulistyawan, 2015).

Pembuatan program kerja sebuah organisasi harus melalui empat proses yang harus dilewati yaitu:

a. Penelitian dan mendengarkan. Dalam tahap ini pengurus organisasi harus mempelajari opini, sikap dan reaksi publik terkait terhadap kebijakan atau produk organisasi yang direncanakan dan akan dilaksanakan.

b. Perencanaan pengambilan keputusan. Dalam hal ini, pengurus organisasi harus bisa memberikan sikap, opini, ide, dan reaksi yang berkaitan dengan kebijaksanaan yang akan dilahirkan. Saat 
dilakukan penetapan program, kerja organisasi harus sejalan dengan kepentingan atau keinginan pihak yang berkepentingan.

c. Mengkomunikasikan dan pelaksanaan. Pengurus organisasi harus menjelaskan informasi mengenai langkah yang akan ditempuh oleh organisasi, dan diharapkan apa yang diputuskan bisa mempengaruhi pihak-pihak tertentu yang penting dan berpotensi mendukung program organisasi.

d. Mengevaluasi. Pengurus organisasi diharapakan mengadakan penilaian dan evaluasi terhadap program dan hasil kerja yang dilakukan (Broom, 2013).

Ketika ketiga tahapan dilakukan maka akan diperoleh proposal yang setidanya memenuhi kriteria. Mengapa tahap keempat tidak menjadi bagian satu kesatuan? Tahap keempat adalah tahapan yang dilakukan ketika proposal telah diunggah dan proposal dinyatakan diterima. Artinya tahapan keempat dibagi menjadi dua bagian yaitu mengevaluasi apa yang akan dilakukan dan apa yang akan dicapai setelah adanya masukan dari reviewer. Mengevaluasi apa yang akan dilakukan yaitu menyamakan hal yang ditawarkan dalam proposal penelitian agar tidak keluar dari yang telah ditawarkan, misalnya mahasiswa menawarkan luaran berupa modul maka evaluasi bagian dari hal mempertahankan luaran tersebut. Kemudian mengevaluasi masukan dari reviewer umumnya terkait kesesuaian waktu dalam mengerjakan proposal yang telah disetujui. Artinya para mahasiswa tidak sekadar membuat proposal yang berfokus hanya pada tahap peunggahan saja melainkan adanya keberlanjutan sehingga penelitian itu berjalan sesuai tabel waktu.

\section{Proposal Penelitian Sebagai Sarana Peningkatan Kemahiran Menulis}

Proposal penelilitian standar Ristekdikti memiliki tingkat kerumitan yang spesifik dan pengerjaan proposal berdasarkan faktor pendukung. Didalam artikel ini, penulis menggunakan definisi faktor pendukung milik Robbin bahwa segala sesuatu yang dapat mendorong seseorang dalam meningkatkan kemampuan pembelajaran untuk menjadi lebih baik dan faktor pendukung itu adalah:

a. Faktor internal, yaitu faktor yang berasal dari dalam diri seseorang baik jasmani (fisiologis) maupun rohani (psikologis). Faktor fisiologis yaitu kondisi umum jasmani dan tonus (tegangan otot) yang menandai tingkat kebugaran organ-organ tubuh dan sendi-sendinya dapat mempengaruhi semangat dan intensitas seseorang dalam mengikuti pelajaran.

b. Faktor eksternal, yaitu faktor yang berasal dari luar diri seorang. Faktor eksternal ini dibagi menjadi dua, yaitu lingkungan (yang berasal dari alam maupun sosial budaya) dan instrumental 
(fasilitas serta media yang disediakan di lembaga pendidikan) (Broom, 2013).

Di dalam pengabdian ini, diketahui bahwa mahasiswa IKM NTT memiliki kelemahan dalam menghasilkan proposal penelitian dikarenakan faktor eksternal seperti literatur dalam perpustakaan yang belum diperbarui, metode yang diajarkan dalam kelas berbeda dengan metode yang dikehendaki oleh Ristekdikti, pelatihan penulisan proposal yang tidak sering dilaksanakan serta kebiasaan menulis ilmiah yang masih rendah. Khusus dalam hal metode penelitian, penulis memberikan contoh dalam fakultas hukum dimana hanya mengenal metode penelitian normatif dan empiris. Perlu dipahami bahwa penelitian hukum tergantung apa yang ditulis dan apa yang dihasilkan (Van Hoecke, 2016). Tetapi pertentangan lainnya muncul ketika metode yang digunakan tergantung dari pemahaman peneliti sendiri. Hal ini berarti bahwa proposal penelitian bisa menyesuaikan dengan metode yang tidak lazim digunakan dalam fakultas hukum (Dent, 2017). Metode penelitian normatif lebih menekankan pada peraturan perundang-undangan sedangkan metode penelitian empiris lebih menekankan peneliti untuk terjun langsung ke lapangan. Tetapi ada juga fakultas hukum yang menekankan pada metode penelitian hukum tanpa adanya pembagian normatif atau empiris. Perkembangan selanjutnya, metode penelitian mengarah pada penafsiran hukum, sosiologi hukum dan hingga saat ini jarang universitas yang menggunakan campuran pada metode penelitiannya.

Akibat hukumnya, peneliti dalam fakultas hukum di Indonesia terpecah-pecah dan selalu mengunggulkan metode penelitiannya adalah yang terbaik. Makna terbaik bukanlah hasil penelitiannya tetapi di antara metode penelitian normatif maka metode penelitian normatif universitas milik $\mathrm{x}$ adalah terbaik dibandingkan universitas milik $\mathrm{v}$. Kepemilikan di universitas merujuk pada sedikit pemikiran ahli hukum dalam universitas tersebut dan sivitas akademika didalamnya akan mengikuti karena sivitas akademika tersebut umumnya mahasiswanya sendiri (Michael, 2018). Artinya kesalahan terdapat pada bagian pendidikan yang tidak membuka diri pada perkembangan ilmu hukum terbaru. Pada akhirnya, ketika mahasiswa fakultas hukum ingin membuat proposal penelitian standar Ristekdikti akan kesulitan karena menggunakan metode pendekatan kualitatif berbasis data.

Kebiasaan menulis ilmiah yang masih menggunakan metode kutipan berdasarkan literatur merupakan kesulitan dalam membuat proposal penelitian karena hasil wawancara adalah hal utama dalam menyiapkan penelitian. Hasil wawancara bukanlah hasil akhir melainkan hasil untuk memulai dalam hal pembuatan latar belakang. Ketika mahasiswa melakukan wawancara maka akan memunculkan sikap aktif untuk memperoleh perkiraan hasil penelitian. Pengalaman berhadapan dengan 
orang lain serta tipe kepribadian yang berbeda akan membiasakan mahasiswa pada kemampuan berkomunikasi dan menyampaikan pendapat secara efektif (Leny \& Suyasa, 2006).

Di dalam pengabdian juga dilakukan pembuatan rancangan proposal dimana masing-masing mahasiswa akan menjelaskan latar belakang penelitian dan kelebihannya. Dalam latar belakang, para mahasiswa menguraikan tinjauan pustaka dan tidak memasukkan contoh kasus terbaru yang mendukung penelitian tersebut. Dengan demikian, latar belakang berfokus pada penjelasan konseptual dan telah menghasilkan data dari rumusan masalah. Faktor kelebihan dari proposal penelitian menghasilkan daya guna yang luas, hal ini menjadikan penelitian tersebut dapat diterapkan secara langsung oleh masyarakat atau peneliti yang bersangkutan. Kelebihan yang ditawarkan adalah kelebih secara sederhana namun bersifat rasional dalam sudut pandang keilmuan.

\section{SIMPULAN DAN SARAN}

Dalam pengabdian masyarakat ini para mahasiswa mendapatkan pemahaman secara komprehensif akan proposal penelitian yang memenuhi kualifikasi Ristekdikti. Adanya perancangan proposal penelitian dan pemaparan secara individual menjadikan mahasiswa siap secara maksimal untuk mengetahui apakah penelitian yang digagasnya dapat dilaksanakan secara rasional atau tidak.

Penulis memberikan beberapa saran yaitu:

1. Pelatihan proposal penelitian berkualifikasi standar Ristekdikti harus menjadi kegiatan ilmiah rutin di Untag Surabaya guna meningkatkan soft skill para mahasiswa. Fakultas sebagai pihak yang meneruskan visi dan misi universitas harus lebih menerapkan pengetahuan dan keterampilan dan memasukkannya dalam kurikulum di kelas. Bandingkan dengan pernyataan "lecturers' and instructors' understanding of soft skills could effectively happen when they have gone through a formal teaching and learning practiceject into any other discipline they are teaching" (Meeks \& Meeks, 2017).

2. Peningkatan literatur online yang memadai dan akses internet

3. Untuk peneliti selanjutnya agar melakukan pengabdian yang berfokus pada tema penelitian yang lintas keilmuan. Sebagai contoh, mahasiswa Fakultas Hukum dapat berkerjasama dalam dengan mahasiswa Fakultas Ilmu Budaya Program Studi Sastra Inggris untuk mengetahui makna pasal dalam suatu undang-undang. Mahasiswa Fakultas Psikologi dapat melakukan kerjasama penelitian dengan mahasiswa Fakultas Hukum untuk mengetahui kajian psikologi hukum terhadap seseorang yang melakukan kejahatan berulang. Kajian penelitian lintas fakultas sangat penting untuk menciptakan luaran yang beragam seperti modul, buku referensi, hak cipta dan artikel jurnal ilmiah. 


\section{UCAPAN TERIMA KASIH}

Penulis mengucapkan terima kasih kepada Lembaga Pengabdian Pada Masyarakat (LPPM) Universitas 17 Agustus 1945 Surabaya, IKM NTT Untag Surabaya dan Kristoforus Laga Kleden yang telah mendanai kegiatan pengabdian ini sehingga terlaksana dengan baik.

\section{DAFTAR RUJUKAN}

Broom, G. M. (2013). Cutlip and Center's Effective Public Relations: International Edition (11th ed.). Pearson Education Limited.

Cimatti, B. (2016). Definition, development, assessment of soft skills and their role for the quality of organizations and enterprises. International Journal for Quality Research, 10(1), 97-130. https://doi.org/10.18421/IJQR10.01-05

Dent, C. (2017). A Law Student-Oriented Taxonomy for Research in Law. Victoria University of Wellington Law Review, 48(2), 371. https://doi.org/10.26686/vuwlr.v48i2.4748

Direktorat Riset dan Pengabdian Masyarakat, Direktorat Jenderal Penguatan Riset dan Pengembangan Kementerian Riset, Teknologi, dan P. T. (PPPKM X. (2018). Panduan Penelitian Dan Pengabdian Kepada Masyarakat Edisi XII Tahun 2018. Jakarta.

Leny, \& Suyasa, P. T. Y. S. (2006). Keaktifan Berorganisasi Dan Kompetensi Interpersonal. Jurnal Phronesis, 8(1), 71-99.

Majid, S., Liming, Z., Tong, S., \& Raihana, S. (2012). Importance of Soft Skills for Education and Career Success. International Journal for Cross-Disciplinary Subjects in Education, 2(Special 2), 1036-1042. https://doi.org/10.20533/ijcdse.2042.6364.2012.0147

Meeks, G. A., \& Meeks, G. (2017). Critical Soft Skills to Achieve Success in the Workplace This is to certify that the doctoral study by.

Michael, T. (2018). Pergerakan Fakultas Hukum Dalam Dimensi tri Dharma (Modernitas Dan Ortodoks). Prosiding Call For Paper Dan Pengabdian Masyarakat Dalam Rangka Dies Natalis Ke-60 Universitas 17 Agustus 1945 Surabaya, 6.

Mustika Cahyaning Peritiwi, Awang Sulistyawan, I. R. dan H. U. K. (2015). Hubungan Organisasi Dengan Mahasiswa Dalam Menciptakan Leadership (Prosiding Seminar Nasional dan Call for Papers Pendidikan Guru Sekolah Dasar Universitas Muhammadiyah Surakarta).

Van Hoecke, M. (2016). Methodology of Comparative Legal Research. Law and Method. https://doi.org/10.5553/rem/.000010 


\section{DOKUMENTASI KEGIATAN}

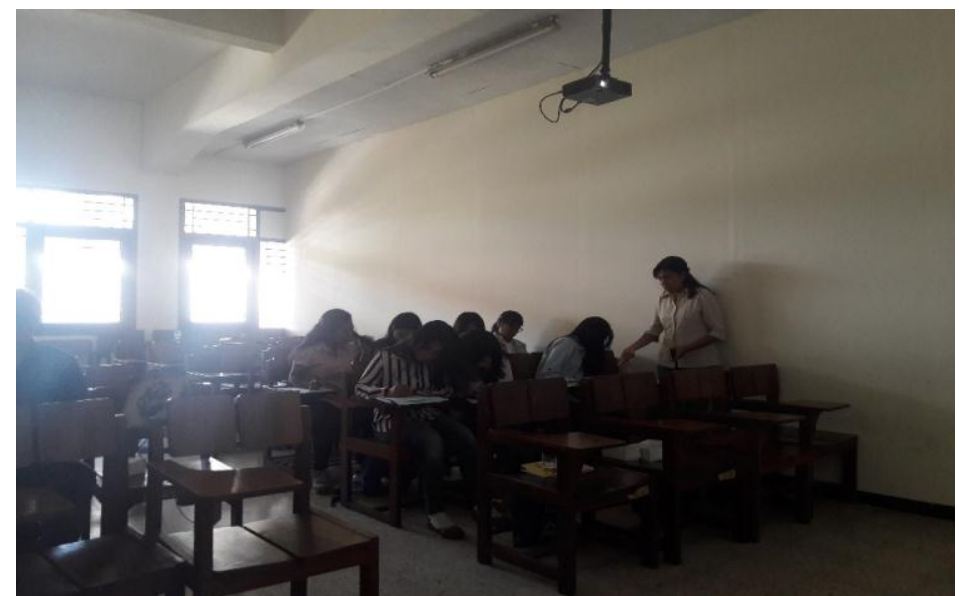

Gambar 1. Mahasiswa IKM NTT sedang membuat rancangan proposal penelitian.

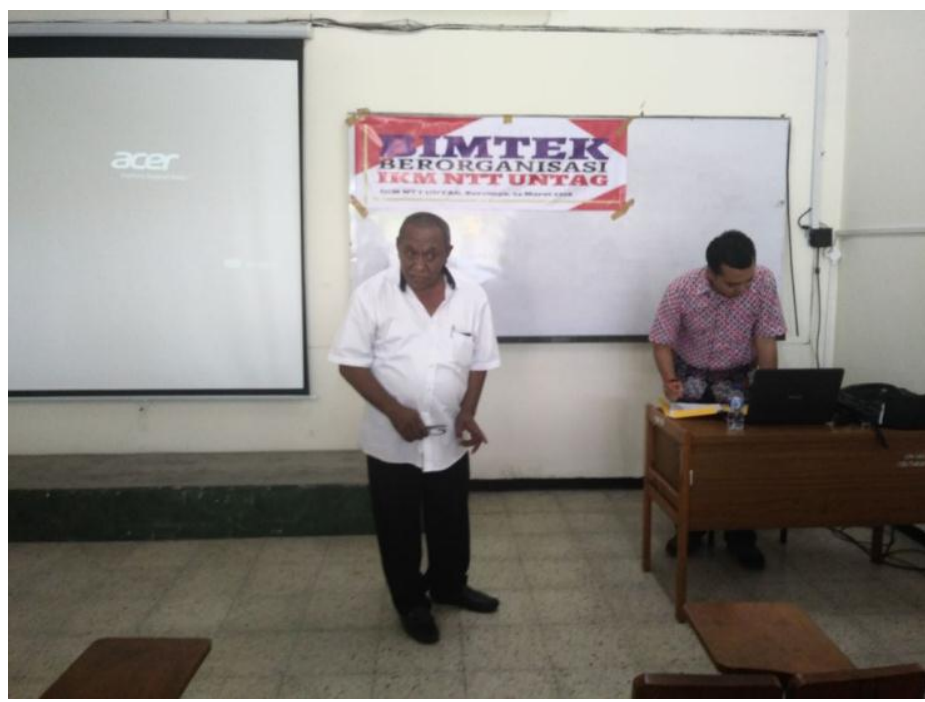

Gambar 2. Pembukaan oleh ketua panitia Kristoforus Laga Kleden.

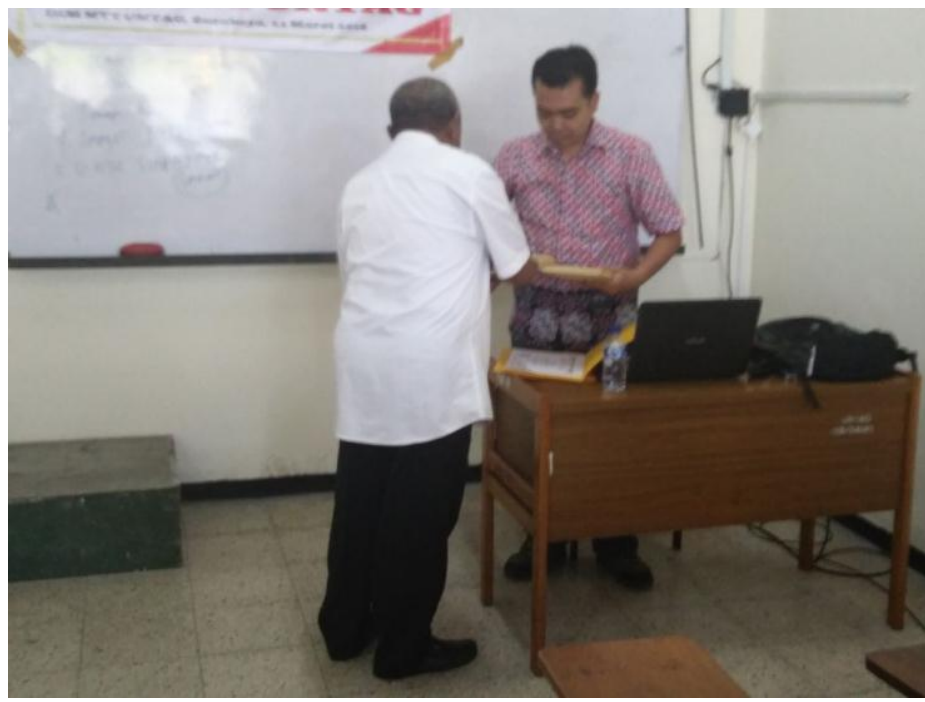

Gambar 3. Penyerahan contoh proposal penelitian yang telah dikerjakan sebelum bimbingan teknis dilaksanakan. 


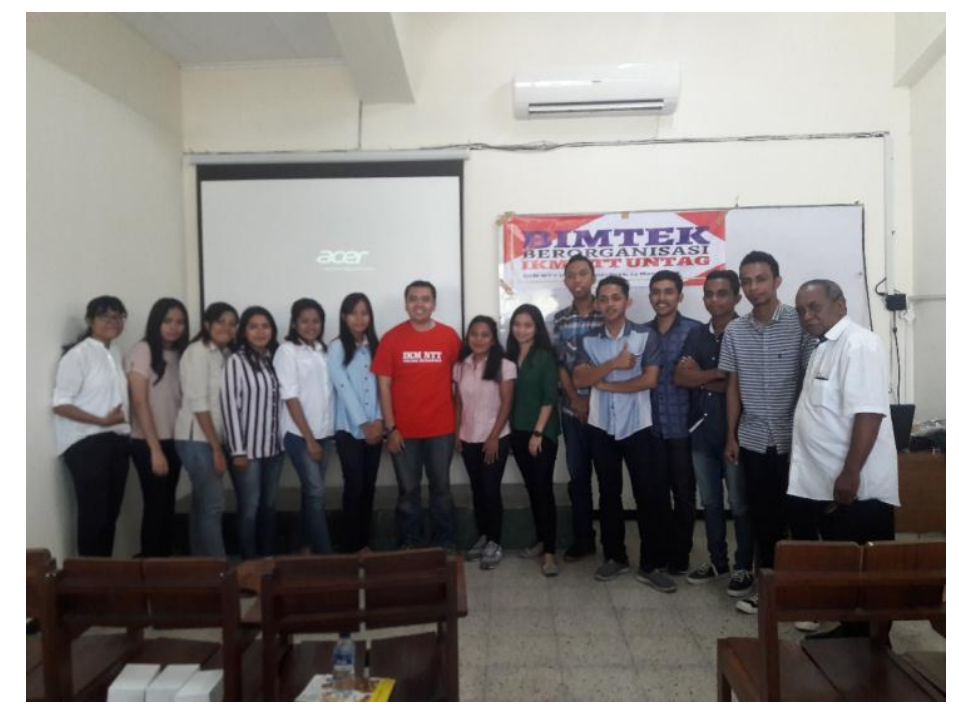

Gambar 4. Foto bersama dengan mahasiswa IKM NTT 